\title{
The extreme environment of a library: Xerophilic fungi inhabiting indoor niches
}

\author{
Anna Micheluz ${ }^{\text {a, }}$, Sabrina Manente ${ }^{b}$, Valeria Tigini ${ }^{c}$, Valeria Prigione ${ }^{c}$, Flavia Pinzari ${ }^{d}$, \\ Giampietro Ravagnan ${ }^{\mathrm{b}}$, Giovanna Cristina Varese ${ }^{\mathrm{c}}$ \\ a Department of Environmental Sciences, Informatics and Statistic, Ca' Foscari University of Venice, Calle Larga S. Marta, 2137, Dorsoduro, \\ 30123 Venice, Italy \\ b Department of Molecular Sciences and Nanosystems, Ca' Foscari University of Venice, Calle Larga S. Marta, 2137, Dorsoduro, 30123 Venice, Italy \\ ${ }^{c}$ Department of Life Sciences and Systems Biology, University of Turin, Viale Mattioli 25, 10125 Turin, Italy \\ ${ }^{\mathrm{d}}$ Consiglio per la Ricerca e la sperimentazione in Agricoltura, Rome 00184, Italy
}

\section{A R T I C L E I N F O}

\section{Article history:}

Received 6 November 2014

Received in revised form

22 December 2014

Accepted 23 December 2014

Available online

\section{Keywords:}

Eurotium halophilicum

Book deterioration

Indoor environment

Airborne population

Compactus shelving

\begin{abstract}
A B S T R A C T
The use of Compactus shelves by libraries and archives is a good solution to optimize the storage space and prevent dust deposits on books. However, they are probably the cause of severe cases of fungal colonization in historical library materials. A typical phenomenon occurs as a spread of white mycelial growth forming scattered spots, mainly on volumes with leather or fabric bindings. Recent studies have identified the xerophilic fungus Eurotium halophilicum (anamorph Aspergillus halophilicus) as responsible for this kind of contamination. A similar situation was found inside the Library of Humanities (BAUM), at Ca' Foscari University, Venice (Italy). Various sampling methods, including cotton swabs and adhesive tape, were adopted to isolate fungi from books and a set of aerobiological analyses was performed to characterize the environment of the repository. The presence of E. halophilicum on both books and in the indoor air was confirmed by direct observation of adhesive tape samples, microscopic observations and molecular methods. Moreover, Aspergillus creber and Aspergillus protuberus belonging to the revised group Aspergillus section Versicolores, were also isolated for the first time in Italian conservation environments.
\end{abstract}

๑) 2014 Elsevier Ltd. All rights reserved.

\section{Introduction}

The proper management of particular indoor environments, such as libraries or museums, is not always adequate to preserve their contents from various kinds of degradation. The best environmental conditions for preserving books and paper products, according to the Italian recommendations (MIBAC, 2001), are $19-24^{\circ} \mathrm{C}$ air temperature and $50-60 \%$ relative humidity. However, these conditions turn out to be suitable for the development and growth of several microfungi and bacteria which need little free water and which can colonise materials with a very low water

\footnotetext{
* Corresponding author. Tel.: +39 041234 8939; fax: +39 0412348977.

E-mail addresses: anna.micheluz@unive.it (A. Micheluz), manente@unive.it (S. Manente), valeria.tigini@unito.it (V. Tigini), valeria.prigione@unito.it (V. Prigione), flavia.pinzari@entecra.it (F. Pinzari), gprav@unive.it (G. Ravagnan), cristina.varese@unito.it (G.C. Varese).
}

activity (Hocking, 1993; Slonczewski et al. 2010; Borrego et al. 2012; Lavin et al. 2010).

Over the last few years, some authors have described a peculiar fungal colonization associated with books in several Italian archives and libraries (Pinzari and Montanari, 2011; Montanari et al. 2012). In all the cases, the damaged books were stored inside movable shelves of the Compactus type, i.e. closed metal cabinets which, sliding on guide rails, can be compacted and therefore minimize the space required for book storage. These kinds of shelves are considered suitable for preserving books from light degradation and dust deposits. However, without an efficient climate control system, movable shelves can create a microenvironment which supports the growth of particular fungal species, involving the spread of infections which damage books as white spots of mycelium appear on them. The main agent responsible for this kind of fungal contamination has been identify as Eurotium halophilicum C.M. Chr., Papav. \& C.R. Benj. (anamorph Aspergillus halophilicus), a xerophilic fungus with high tolerance to water stress. The minimum water activity observed for its 
germination and growth of this species is 0.675 (Christensen et al. 1959). Because of its particular requirements, this fungus has been isolated from dry food and indoor dust in association with Aspergillus penicillioides and dust mites (Christensen et al. 1959; Samson and Lustgraaf, 1978; Hocking and Pitt, 1988; AbdelHafez et al. 1990; Aiqing et al. 2011). It has recently been associated with books and paper biodeterioration, and in particular to the presence of very particular micro-niches inside museums, libraries or archives, capable of developing also when the overall environmental conditions seem perfect for the conservation of Cultural Heritage. These niches are characterised by scarce ventilation and the presence of a water vapour gradient that can lead to the condensation on some particular materials after sudden drop of temperature or night-day thermo hygrometric cycles. These peculiar, often very local, conditions together with soaking events in usually dry environments seemed to favour the development of osmophilic and xerophilic fungal species (Michaelsen et al. 2010; Sterflinger, 2010; Pinzari and Montanari, 2011; Montanari et al. 2012). Similar colonization patterns and microscopic features observed in several Italian case studies suggest that E. halophilicum might have a large distribution in repositories with Compactus shelves, but its detection may be largely underestimated. Inadequacy of sampling procedures and the very slow growth of the fungus on most media are probably the main reasons for previous underestimations.

In the spring of 2013, a widespread fungal contamination was discovered inside one of the libraries of Ca' Foscari University, Venice (Italy). Stored on Compactus shelves, more than 27,000 old books were found to be spotted with a white growth similar to typical colonization by E. halophilicum and the aim of this study was to verify if it is indeed due to this fungus. Aerobiological analyses were carried out to characterize the repository environment in order to find a connection between airborne fungi and the observed phenomena of book deterioration.

\section{Materials and methods}

\section{Sampling area}

Sampling was performed in a repository of the Library of Humanities (Biblioteca di Area Umanistica, BAUM), at Ca' Foscari University, Palazzo Malcanton Marcorà, in Venice (Italy). The repository covers an area of about $150 \mathrm{~m}^{2}$, is located in the second underground floor, and is furnished with 50 two-row Compactus shelves. After an initial inspection in early 2013, the origin of the fungal colonization was identified in a corner far from the entrance, marked Area 1 in Fig. 1a. In this area, the manuscripts and oldest books of the University collection were stored inside blocks of shelves, which had been kept closed for several months, because of the damage to the sliding tracks (pers.comm. library director).

The fungal growth had spread to eight neighbouring Compactus shelves and was also found on some isolated volumes stored in five shelves of the second row. More than 27,000 Cinquecentine, manuscripts and books, especially volumes with leather or fabric bindings dating to the XVI-XIX centuries and belonging to the historical collection of Ca' Foscari University, had been colonized by a white spotted growth (Fig. 1b). The environmental conditions of the repository corresponded to the recommendations of the Italian Ministry for Cultural Heritage $\left(\mathrm{T}=23^{\circ} \mathrm{C}\right.$ and $\mathrm{RH}=56.3 \%$ ) (MIBAC, 2001), but apparently, a lack of ventilation inside the Compactus shelves and condensation of water on the books during winter, due to lowered environmental temperature, had probably promoted the germination of fungal spores and allowed contamination to spread.

\section{Book sampling}

Five books were sampled with various methods to isolate the fungal colonies: (1) sterile cotton swabs (Cultiplast, LP Italiana Spa, Milan, Italy) were wiped over the spots which had developed on the spines of bindings and then inoculated in 9-cm Petri dishes; (2) sterile nitrocellulose membranes (Advantec MFS, Inc., Dublin, CA, USA; $0.45 \mathrm{~m}$ pore size, $47 \mathrm{~mm}$ diameter) were gently pressed on the spots visible to the naked eye on the covers of contaminated books for $10 \mathrm{~s}$ and then transferred to Petri dishes; (3) pieces $(6 \times 2 \mathrm{~cm})$ of Fungi-Tape $^{\mathrm{TM}}$ (Scientific Device Laboratory, Des Plaines, IL, USA; $1 \mathrm{~mm}$ thick, no. 745) were pressed over the spots to collect fungal structures and then deposited on sterile glass slides for microscopic observation; (4) active sampling with Sampl'air Lite (Biomérieux, Florence, Italy) with an air sample volume of $100 \mathrm{~L}$ (flow rate $100 \mathrm{~L} /$ min) was performed directly from the book covers, fungal structures being collected directly into Petri dishes. As a result of a previous selection of low water activity media, Malt Extract Agar added with $15 \% \mathrm{NaCl}$ (MEA 15\%) (Christensen et al. 1959) and supplemented with $0.05 \mathrm{~g} / \mathrm{L}$ chloramphenicol to limit bacterial development was used as the most appropriate selective culture medium. All the Petri dishes containing the inocula were then transferred to the laboratory and incubated at $25^{\circ} \mathrm{C}$ for $7-14$ days.

\section{Microbial air sampling}

The air inside and outside the repository was analysed, to determine the level of fungal contamination. Five sampling areas were chosen according to a centrifugal scheme related to the primary colonization area and in respect to the single point of entrance/exit (i.e., of air exchange; Fig. 1a). Three replicas were made for each location. Both active and passive sampling was carried out to collect fungi directly from the air and the hourly viable particles settling on surfaces. To verify the presence of $E$. halophilicum and, in general, of xerophilic and halophylic fungi, MEA $15 \%$ supplemented with $0.05 \mathrm{~g} / \mathrm{L}$ chloramphenicol was chosen to collect airborne fungi. Active sampling was performed with a Sampl'air Lite sampler (Biomérieux, Florence, Italy) with 9-cm Petri dishes, flow rate $100 \mathrm{~L} / \mathrm{min}$ and sample volume of $100 \mathrm{~L}$. The sampler was placed $1.5 \mathrm{~m}$ above the floor, to represent the breathing zone of a standing person. The total numbers of colonyforming units (CFU) in each sample were calculated according to the conversion table provided by the supplier; results are presented as CFU per cubic meter of air (CFU/m²) (Peto and Powel, 1970).

For passive sampling, 9-cm Petri dishes were exposed to air particles for $1 \mathrm{~h}, 1 \mathrm{~m}$ above the floor and at a distance of about $1 \mathrm{~m}$ to obstacles, to determine the Index of Microbial Air Contamination (IMA) expressed as CFU/dm² $/ \mathrm{h}$ (Pasquarella et al. 2000).

After samplings, the dishes were closed, labelled, transferred to the laboratory and incubated at $25^{\circ} \mathrm{C}$ for $7-14$ days.

\section{Optical and scanning electronic microscopic observation of sample tapes}

The strips of adhesive tape (Fungi-Tape ${ }^{\mathrm{TM}}$ ) used for sampling the book bindings were observed under a optical microscope (Axio plan, Zeiss, Germany) at $200 \times$ and $400 \times$ magnification. Micrographs were acquired with a digital camera (AxioCam ERc5s, Zeiss) connected to a PC with ZEN 2011 software (Zeiss).

Fragments of tapes were observed under an EVO 50 (Zeiss), scanning electron microscope (SEM). The tapes were placed in phosphate buffer ( $\mathrm{pH} 7.0$ ), fixed in glutaraldehyde buffer for $2 \mathrm{~h}$, rinsed in distilled water, post-fixed in $2 \% \mathrm{OsO}_{4}$ for $12 \mathrm{~h}$ at $5{ }^{\circ} \mathrm{C}$, dehydrated in an ethanol series, taken to amyl acetate, and critical point-dried in a Polaron E-3000 dryer (Quorum Technologies, 

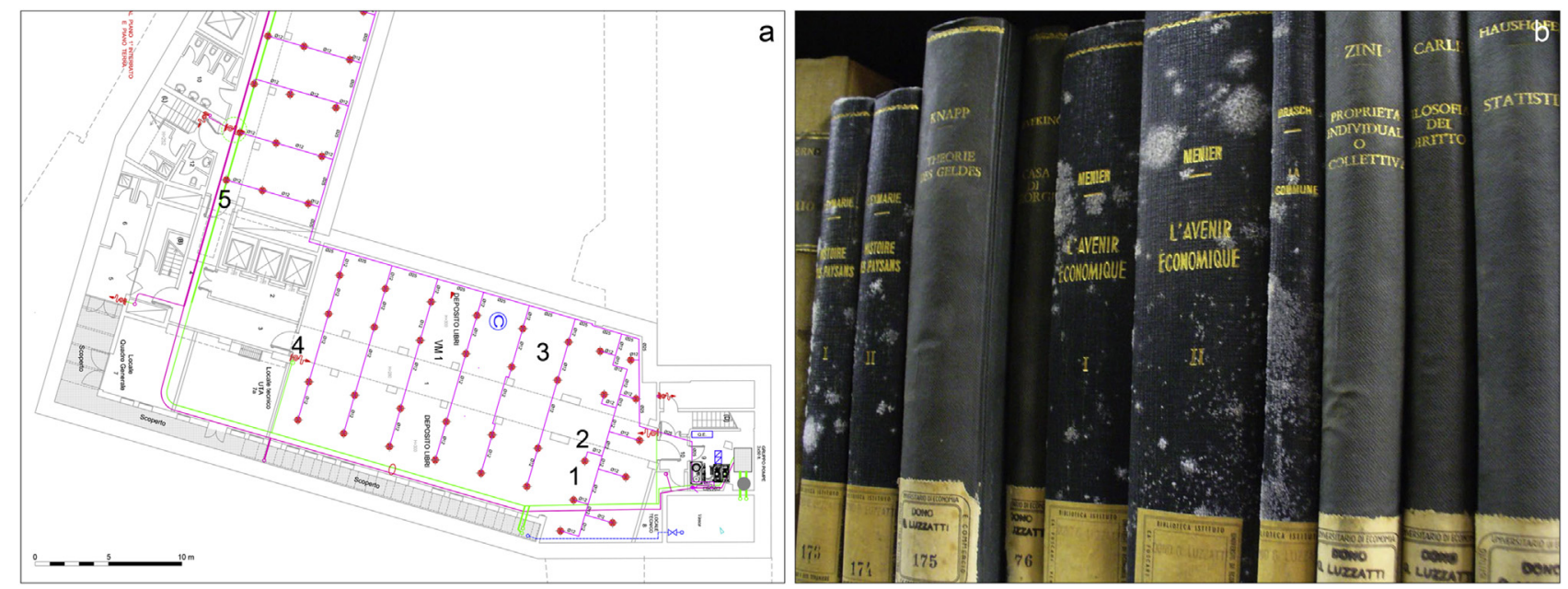

Fig. 1. a: Map of the five sampling areas inside the repository of Library of Humanities (BAUM), Ca' Foscari University, Venice (Italy). b: white fungal growth on book covers.

Ringmer, UK) with carbon dioxide. The samples were then coated with gold (Baltec Sputter Coater) for analysis in High Vacuum mode. Sputtering was performed under an Argon gas flow at a working distance of $50 \mathrm{~mm}, 0.05 \mathrm{mbar}$ of pressure and $40 \mathrm{~mA}$ current for $60 \mathrm{~s}$, to obtain a gold film about $15 \mathrm{~nm}$ thick. Some samples were gold-coated and observed by SEM without previous fixation, to evaluate any formation of artefacts and the natural degree of dehydration.

\section{Fungal identification}

Fungi were identified with a polyphasic approach which couples morpho-physiological features with molecular studies. After determination of genera according to macroscopic and microscopic features (Christensen et al. 1959; Raper and Fennell, 1965; Pitt, 1979; Pitt and Hocking, 1997; Klich, 2002; Samson et al. 2004), the fungal strains were transferred to the media recommended by the authors of selected genus monographs for species identification. Molecular identification was performed by amplification and sequencing of internal transcribed spacers (ITS), $\beta$-tubulin and actin genes (White et al. 1990; Gardes and Bruns, 1993; Carbone and Kohn, 1999; Bensch et al. 2012). The resulting sequences were compared with reference sequences in online databases provided by the CBS-KNAW Fungal Biodiversity Centre (The Netherlands) and the NCBI National Center for Biotechnology Information (US). The fungal sequences and corresponding species identifications were deposited in GenBank under accession numbers KM264279-KM264297 and KM502176-KM502208. All fungi are preserved at the Mycotheca Universitatis Taurinensis (MUT) of the Department of Life Sciences and Systems Biology, University of Turin (Italy).

\section{Statistical analyses and diversity assessment}

The Bray-Curtis Index was applied to the airborne microbial population in order to describe similarity among sampling areas, with XLSTAT 2014.4.01. A significant dissimilarity level of 0.95 was applied. The Simpson Diversity Index was also calculated to explain the level of species diversity inside the repository, according to the formula: $1-D=1-\sum(n / N)^{2}$, where $n$ is the number of colonies per morphological fungal species and $\mathrm{N}$ is the total frequency of the corresponding colony in the population (Magurran, 1988; Nunes et al. 2013).

\section{Results and discussions}

\section{Book sampling}

The uniform spread of fungal colonization was visible to the naked eye on all sampled books, as white spots of varying sizes, ranging on average from 0.2 to $1 \mathrm{~cm}$ in diameter (Fig. 1b). Direct observation of Fungi-Tape ${ }^{\mathrm{TM}}$ samples by optical microscope showed various fungal structures, such as mycelium, conidiophores and conidia, mainly belonging to Aspergillus spp. Uniseriate radiate to columnar conidial heads and ellipsoidal conidia of quite variable size $(5-7.5 \times 5-9 \mu \mathrm{m})$ were observed. The shape, ornamentation and dimensions of these conidia were consistent with those of the anamorphous state of E. halophilicum, namely Aspergillus halophilicus (Fig. 2) (Samson and Lustgraaf, 1978). Short bare "hairs" on the hyphae were visible even at $200 \times$ magnification, and even clearer under SEM. These hairs were found in fixed, gold-coated and directly sputtered samples, thus confirming that they were not an artefact of preparation.

Fourteen species belonging to eight genera were identified (Table 1). Sterile swabbing, nitrocellulose membranes and active sampling favoured the isolation of five, nine and eight taxa, respectively. Although the nitrocellulose membranes isolated the highest number of species, they did not isolated E. halophilicum. Instead, active sampling isolated all the species isolated by sterile swabbing and also some others. Several authors have already demonstrated the effectiveness of nitrocellulose membranes for fungal isolation from varying types of substrates (e.g., Florian, 2002; Manente et al. 2012). The most frequent fungal species found in our case were Aspergillus creber and Penicillium brevicompactum. A. creber, belonging to the recent revisited section Versicolores (Jurjevic et al. 2012), was found on stored books for the first time; $P$. brevicompactum is well-known as one of the most xerophilic Penicillia (Hocking and Pitt, 1988). E. halophilicum was preferentially isolated by sterile swabbing and active sampling very close to the contamination on the books. Although its white growth was visible on all the book covers, its isolation was difficult and sporadic, and samples were obtained from only one volume. These results match literature reports of this species. After initial largescale expansion, due to the sudden availability of water on the books, identifiable as mycelium sporification, E. halophilicum stops growing and its starving mycelium acts passively as a sort of trap for other airborne spores. A hypothesis still to be proven is that this 

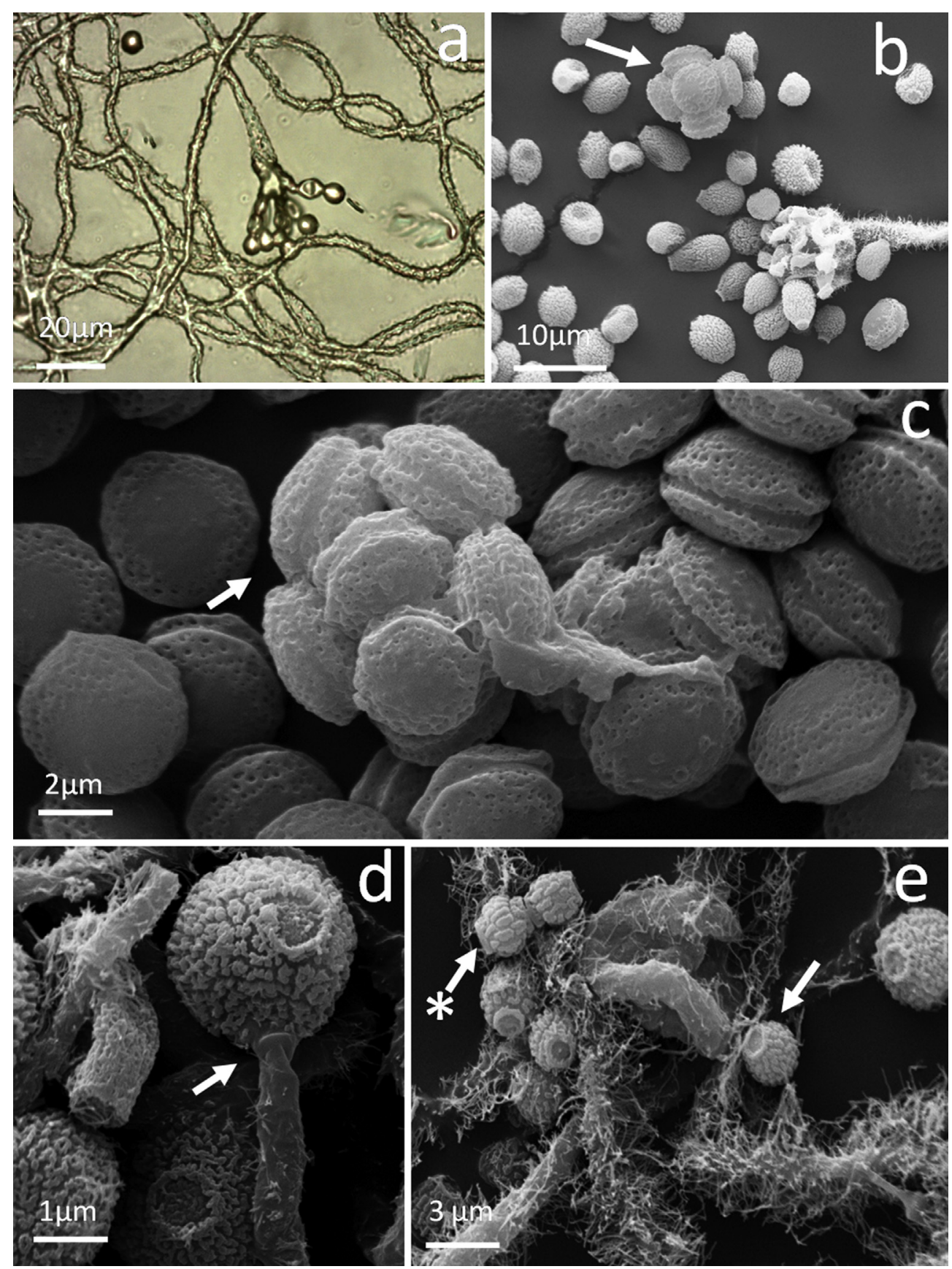

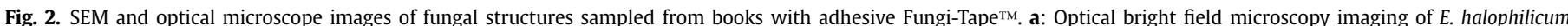

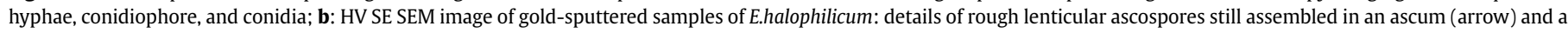

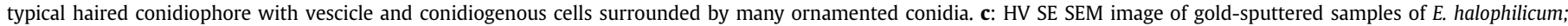

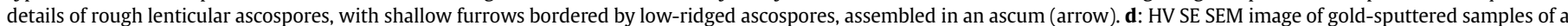

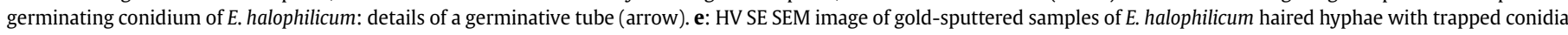

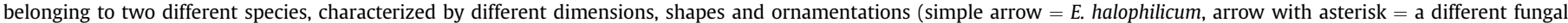
species).

starving mycelium provides the substrate for the growth or survival of spores and propagules of other fungi. This may explain why old contaminations in libraries are due to fungal species other than the E. halophilicum, although its presence on materials can very often be documented by molecular methods and SEM imaging.

Colonies of another xerophilic fungus, $A$. penicillioides, were also frequently isolated from books. Already in 1978, this fungus was associated with E. halophilicum by Samson and Lustgraaf (1978) as cohabiting in house dust, emphasizing the possibility what it was responsible for allergic reactions and lung disease. This species was also been isolated from dry food and indoor environments, such as museums, archives, shelving and carpeting (Samson and Lustgraaf, 1978; Pitt and Hocking, 1997; Samson et al. 2004). In particular, A. penicillioides has often been associated with the mycoflora isolated from old contaminated books and manuscripts (Pinzari and Montanari, 2008; Michaelsen et al. 2010; Montanari et al. 2012). 
Table 1

Fungal diversity from various sampling procedures on books, with GenBank accession numbers.

\begin{tabular}{|c|c|c|c|}
\hline Fungal species & Number of books & Methods of isolation & Accession number \\
\hline Aspergillus creber Jurjevic, S.W. Peterson \& B.W. Horn & 4 & $\mathrm{~S}, \mathrm{~A}, \mathrm{M}$ & $(*)$ \\
\hline Penicillium brevicompactum Dierckx & 3 & $\mathrm{~S}, \mathrm{~A}, \mathrm{M}$ & KM502183 \\
\hline Aspergillus penicillioides Speg. & 3 & $\mathrm{~S}, \mathrm{~A}$ & KM502180 \\
\hline Aspergillus protuberus Munt.-Cvetk. & 2 & $\mathrm{~S}, \mathrm{~A}$ & $(*)$ \\
\hline Eurotium halophilicum C.M. Chr. Papav. \& C.R. Benj. & 1 & S, A & KM502179 \\
\hline Aspergillus jensenii Jurjevic, S.W. Peterson \& B.W. Horn & 1 & A & KM502178 \\
\hline Lecanicillium kalimantanense Kurihara \& Sukarno & 1 & A & KM264285 \\
\hline Eurotium chevalieri L. Mangin & 1 & M & $(*)$ \\
\hline Aspergillus versicolor (Vuill.) Tirab. & 1 & M & KM264292 \\
\hline Penicillium chrysogenum Thom & 1 & M & $\left({ }^{*}\right)$ \\
\hline Cladosporium ramotenellum K. Schub., Zalar, Crous \& U. Braun & 1 & M & KM264294 \\
\hline Epicoccum nigrum Link & 1 & M & KM264283 \\
\hline Phaeospheria typharum (Desm.) L. Holm & 1 & M & KM264282 \\
\hline Gloeophillum abietinum (Bull.) P. Karst. & 1 & M & KM264291 \\
\hline
\end{tabular}

$\mathrm{S}=$ sterile swab; $\mathrm{A}=$ active sampling; $\mathrm{M}=$ nitrocellulose membrane.

$\left({ }^{*}\right)$ Fungal species that have only been identify using morphological approach.

\section{Microbial air sampling}

The results of microbial air sampling demonstrated a gradually decreasing contamination gradient from area 1 toward the exit of the repository (Table 2). The source of colonization in area 1 was the most contaminated of all the sampled sites, followed by area 2 (2000 and $1620 \mathrm{CFU} / \mathrm{m}^{3}$, respectively) and they presented the highest fungal similarity $\left(\mathrm{d}^{\mathrm{BCS}}=0.84\right)$. These loads were ten times higher than in the other sampled areas, which ranged between 101 and $29 \mathrm{CFU} / \mathrm{m}^{3}$, with low similarity indices $\left(0.06<\mathrm{d}^{\mathrm{BCS}}<0.4\right)$. The total fungal loads in areas 1 and 2 were higher than those reported in similar studies (Karbowska-Berent et al. 2011; Pasquarella et al. 2012; Nunes et al. 2013). They were also higher than the $150 \mathrm{CFU} / \mathrm{m}^{3}$ value recommended for Italian libraries (MIBAC, 2001), and even higher than other international recommended limits, which indicated a maximal contamination value of $1000 \mathrm{CFU} / \mathrm{m}^{3}$ for archives (Borrego et al. 2010; Nunes et al. 2013). The data from passive sampling recorded a lower yield compared with active sampling, with $4-44 \mathrm{CFU} / \mathrm{m}^{2} / \mathrm{h}$. The absence of CFU from the passive sampler in the area 5 may be explained by the lack of settling microbial particles able to grow on the selective media used, or by the different ventilation system outside the repository.

Several fungal patterns were found in the sampled areas, highlighting the variety of mycological species found in a quite small space $\left(150 \mathrm{~m}^{2}\right)$, and the Simpson Diversity Index ranged between 0.5 and 0.9 (Table 2). Area 4 had the highest fungal diversity, perhaps because of the continual passage of workers and students. Area 1 also had the lowest value of fungal variability, perhaps be due to the particular environmental conditions between the shelves, with very low air exchange rates.

Morphological and molecular analysis isolated 76 different fungal taxa, belonging to eleven fungal genera (Table 3 ). Aspergillus was the most frequent genus (82.4\%), followed by Penicillium (14.7\%) and Cladosporium (1.4\%). The remaining isolates presented low frequency, between $0.8 \%$ and $<0.1 \%$. The most abundant species were A. creber (55.7\%), Aspergillus protuberus (25.7\%), Penicillium chrysogenum (11.5\%) and P. brevicompactum (3.1\%), characterizing in particular the colonization source in area 1 and the surrounding area 2. Found also on the sampled books, these species are common indoor fungi (Samson et al. 2004; Jurjevic et al. 2012). $P$. chrysogenum and $P$. brevicompactum, in particular, have also been associated with the biodeterioration of Cultural Heritage materials (Zyska, 1997; Montemartini Corte et al., 2003; Sterflinger, 2010). Conversely, the genera Cladosporium (1.4\%) was peculiar to transition areas 4 and 5, together with other outdoor fungi such as Pleosporales sp., Embellisia sp., Schyzophillum sp. and Botrytis sp. (Pitt and Hocking, 1997; Samson et al. 2004). Area 3 showed a mixture of fungi also found in the other areas, both indoor, such as Aspergillus spp. and Penicillium spp. (Gallo, 1993; Zyska, 1997; Sterflinger, 2010) and outdoor, such as Fusarium sp. and Alternaria sp., were found (Pitt and Hocking, 1997; Samson et al. 2004).

Fungi collected with passive sampling were limited to a few colonies of A. penicillioides, Aspergillus proliferans, Penicillium corylophilum and Penicillium italicum. Active sampling may have revealed their presence, but they could not be isolated due to the high number of $\mathrm{CFU} / \mathrm{m}^{3}$.

The sampled air did not allow isolation of colonies of E. halophilicum. This result emphasizes how the presence of this fungus may easily be neglected or underestimated during air quality and conservation surveys in libraries and archives, as it is difficult to isolate from the air and grows slowly in vitro.

\section{Conclusions}

Fungal contamination caused by a proliferation of $E$. halophilicum was identify inside the Library of Humanities (BAUM) at Ca' Foscari University, Venice (Italy). Its presence was found on books and in the nearby surrounding indoor air, but could not be isolated by aerobiological analysis, probably because of its poor susceptibility to air dispersion. It appears that it may proliferate and

Table 2

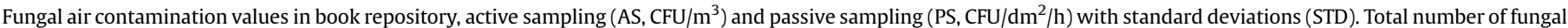
taxa and Simpson Diversity Index presented for each sampled area and for entire environment of repository.

\begin{tabular}{|c|c|c|c|c|}
\hline Sampling areas inside the deposit & $\begin{array}{l}\mathrm{AS}\left(\mathrm{CFU} / \mathrm{m}^{3}\right) \\
\text { mean } \pm \text { st. dev. }\end{array}$ & $\begin{array}{l}\mathrm{PS}\left(\mathrm{CFU} / \mathrm{dm}^{2} / \mathrm{h}\right) \\
\text { mean } \pm \text { st. dev. }\end{array}$ & Number of fungal taxa & Simpson's index of fungal population \\
\hline 1: Right corner far from the entrance, between shelves & $2000 \pm 610$ & $44 \pm 9$ & 5 & 0.5 \\
\hline 2: Corridor close to the area 1 & $1620 \pm 80$ & $35 \pm 8$ & 8 & 0.6 \\
\hline 3: Left corner far from the entrance, between shelves & $81 \pm 1$ & $11 \pm 5$ & 12 & 0.8 \\
\hline 4: Entrance & $101 \pm 12$ & $4 \pm 2$ & 22 & 0.9 \\
\hline 5: Storage room adjacent to the deposit studied & $29 \pm 13$ & 0 & 7 & 0.7 \\
\hline Total & 3831 & 94 & 27 & 0.6 \\
\hline
\end{tabular}


Table 3

Fungal diversity results from aerobiological analysis, expressed for sampled areas as relative frequency, together with GenBank accession numbers.

\begin{tabular}{|c|c|c|c|c|c|c|c|}
\hline \multirow[t]{2}{*}{ Fungal species } & \multicolumn{6}{|c|}{ Relative frequency (\%) } & \multirow[t]{2}{*}{ Accession no. } \\
\hline & Area 1 & Area 2 & Area 3 & Area 4 & Area 5 & Total count & \\
\hline Aspergillus creber Jurjevic, S.W. Peterson \& B.W. Horn & $64.3 \%(\mathrm{P})$ & $50.3 \%(P)$ & $27 \%(P)$ & $14.9 \%$ & - & $55.7 \%$ & KM502191 \\
\hline Aspergillus protuberus Munt.-Cvetk & $23.3 \%(\mathrm{P})$ & $31.5 \%(\mathrm{P})$ & $7 \%$ & $6.9 \%$ & - & $25.7 \%$ & KM502192 \\
\hline Penicillium chrysogenum Thom & $9.5 \%(P)$ & $13.6 \%(\mathrm{P})$ & $20 \%$ & $9.9 \%(P)$ & $3.6 \%$ & $11.5 \%$ & KM502200 \\
\hline Penicillium brevicompactum Dierckx & $2.8 \%$ & $3.4 \%$ & $7 \%$ & $1 \%$ & - & $3.1 \%$ & $(*)$ \\
\hline Aspergillus spp. & - & $(\mathrm{P})$ & $10 \%$ & $2 \%$ & $10.7 \%$ & $0.4 \%$ & $\left({ }^{*}\right)$ \\
\hline Cladosporium pseudocladosporioides Bensch, Crous \& U. Braun & $(\mathrm{P})$ & (P) & $(\mathrm{P})$ & $5 \%(P)$ & - & $0.1 \%$ & $(*)$ \\
\hline Cladosporium cladosporioides (Fresen.) G.A. de Vries & - & - & - & $9.9 \%$ & $46.4 \%$ & $0.6 \%$ & KM264293 \\
\hline Cladosporium ramotenellum K. Schub., Zalar, Crous \& U. Braun & - & $0.3 \%$ & $2 \%$ & $5 \%$ & $14.3 \%$ & $0.4 \%$ & KM264295 \\
\hline Aspergillus penicillioides Speg. & - & $(\mathrm{P})$ & - & - & - & - & $(*)$ \\
\hline Phaeospheria herpotrichoides (De Not.) L. Holm & - & - & - & $2 \%(\mathrm{P})$ & $7.1 \%$ & $0.1 \%$ & KM264281 \\
\hline Aspergillus niger Tiegh. & - & $0.3 \%$ & - & $5 \%$ & - & $0.3 \%$ & KM502177 \\
\hline Penicillium sizovae Baghd. & - & $0.3 \%$ & - & $5 \%$ & - & $0.3 \%$ & KM502185 \\
\hline Botrytis cinerea Pers. & - & - & - & $2 \%(\mathrm{P})$ & - & $0.1 \%$ & KM264280 \\
\hline Aspergillus sydowii (Bainier \& Sartory) Thom \& Church & $(\mathrm{P})$ & - & $1 \%$ & - & - & $<0.1 \%$ & KM502191 \\
\hline Aspergillus proliferans G. Sm. & - & $(\mathrm{P})$ & - & - & - & - & KM502181 \\
\hline Penicillium italicum Wehmer & - & (P) & - & - & - & - & KM502188 \\
\hline Penicillium corylophilum Dierckx & - & - & $(\mathrm{P})$ & - & - & - & KM502184 \\
\hline Pleosporales sp. Luttr. Ex M.E. Barr & - & - & $1 \%$ & $5 \%$ & - & $0.2 \%$ & $(*)$ \\
\hline Cladosporium sphaerospermum Penz. & - & - & - & $5.9 \%$ & - & $0.2 \%$ & KM264296 \\
\hline Aspergillus insuetus (Bainier) Thom \& Church & - & $0.3 \%$ & - & - & - & $0.1 \%$ & KM502182 \\
\hline Cladosporium ossifragi (Rostr.) U. Braun \& K. Schub. & - & - & - & $5 \%$ & - & $0.1 \%$ & $\left({ }^{*}\right)$ \\
\hline Phoma glomerata (Corda) Wollenw. \& Hochapfel & - & - & - & $5 \%$ & - & $0.1 \%$ & KM264279 \\
\hline Penicillium glabrum (Wehmer) Westling & - & - & - & $4 \%$ & - & $0.1 \%$ & KM502187 \\
\hline Eurotium chevalieri L. Mangin & - & - & - & $2 \%$ & $3.6 \%$ & $0.1 \%$ & $\left({ }^{*}\right)$ \\
\hline Fusarium oxysporum Schltdl. & - & - & $2 \%$ & - & - & $0.1 \%$ & KM264286 \\
\hline Aspergillus sclerotiorum G.A. Huber & $(\mathrm{P})$ & - & $1 \%$ & - & - & 0 & KM502176 \\
\hline Aspergillus flavus Link & - & - & - & $1 \%$ & - & $<0.1 \%$ & $(*)$ \\
\hline Embellisia abundans E.G. Simmons & - & - & - & $1 \%$ & - & $<0.1 \%$ & KM264288 \\
\hline Alternaria infectoria E.G. Simmons & - & - & $1 \%$ & - & - & $<0.1 \%$ & KM264290 \\
\hline Schyzophyllum commune Fr. & - & - & - & $1 \%$ & - & $<0.1 \%$ & KM264287 \\
\hline Sterile mycelium & $0.3 \%(\mathrm{P})$ & $(\mathrm{P})$ & $21 \%$ & $2 \%$ & $14.3 \%$ & $0.8 \%$ & $(*)$ \\
\hline
\end{tabular}

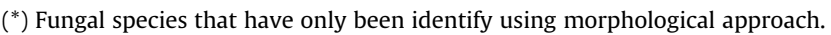

(P) Fungal species isolated by passive sampling.

spread only during its first period of growth, after which, it is difficult to isolate, even from contaminated surfaces with visible fungal growth. This is why its spread may also be attributed to other strategies, such as dust mites. A. penicillioides was also frequently isolated from books in association with E. halophilicum, probably because of the similar behaviour and low water requirements of both these species. Aerobiological analysis revealed high fungal concentrations, exceeding Italian recommended limits for libraries, inside the repository and in particular close to the source of colonization between shelves. A. creber, A. protuberus, $P$. chrysogenum and $P$. brevicompactum were the species most frequently isolated. Moreover, A. creber and A. protuberus belonging to the Aspergillus section Versicolores group were also detected for the first time inside the Italian repository environment. The use of sampling media suitable for halophilic and xerophilic fungal species inside archives and libraries emphasizes a very peculiar ecological dynamic in these indoor environments, as unsuspected and little investigated niches are occupied.

Apart from the biodegradation of very old books, our results should be considered in relation to the effect which these poorly studied fungal species may have on human health. In theory, most of the identified species, such as Aspergillus and Penicillium spp., and their high concentrations in closed environments, may cause health problems for both library workers and visitors. Rapid diagnoses, frequent dusting and effective ventilation should all be ensured, to prevent fungal contamination of materials.

\section{Acknowledgements}

We would like to thank Drs. Antonella Sattin, Alessandra Zorzi and Daniela Grandin, directors and responsible for the library system at Ca' Foscari University in Venice, for their support to this project.

\section{References}

Abel-Hafez, S.I.I., Moubasher, A.H., Barakat, A., 1990. Keratinophilic fungi and other moulds associated with air- dust particles from Egypt. Folia Microbiol. 35, $311-325$.

Aiqing, X., Yuanliang, W., Jieyu, W., Pin, 1, Ziyin, L., Longjjun, L., 2011. Fungal community associated with fermentation and storage of Fuzhan brick-tea. Int. J. Food Microbiol. 146, 14-22.

Bensch, K., Braun, U., Groenewald, J.Z., Crous, P.W., 2012. The genus Cladosporium. Stud. Mycol. 72, 1-401.

Borrego, S. Guiamet, P., Gómez de Saravia, S, Batistini, P. Garcia, M. Lavin, P. Perdomo, I., 2010. The quality of air at archives and the biodeterioration of photographs. Int. Biodeterior. Biodegrad. 64, 139-145.

Borrego, S., Lavin, P., Perdomo, I., Gómez de Saravia, S., Guiamet, P., 2012. Determination of indoor air quality in archives and biodeterioration of the documentary heritage. ISRN Microbiol. 2012, 10.

Carbone, I., Kohn, L.M., 1999. A methods for designing primer sets for speciation studies in filamentous ascomycetes. Mycologia 91, 553-556.

Christensen, C.M., Papavizas, G.C., Benjamin, C.R., 1959. A new halophilic species of Eurotium. Mycologia 51, 636-640.

Florian, M.L.E., 2002. Fungal Facts: Solving Problems in Heritage Collection. Archetype Publications Ltd, London, UK.

Gallo, F., 1993. Aerobiological research and problems in libraries. Aerobiologia 9, $117-130$.

Gardes, M., Bruns, T.D., 1993. ITS primers with enhanced specificity for basiomycetes - application to the identification of mycorrhizae and rusts. Mol. Ecol. 1, $113-118$.

Hocking, A.D., Pitt, J.I., 1988. Two new species of xerophilic fungi and a further record of Eurotium halophilicum. Mycologia 80, 82-88.

Hocking, A.D., 1993. Responses in xerophilic fungi to changes in water activity. In: Jennings, D.H. (Ed.), Stress Tolerance of Fungi. Marcel Dekker, Inc., New York pp. 233-243.

Jurjevic, Z., Peterson, S.W., Horn, B.W., 2012. Aspergillus section Versicolores: nine new species and multilocus DNA sequence based phylogeny. IMA Fungus 3, $59-79$ 
Karbowska-Berent, J., Górny, R.L., Strzelczyk, A.B., Wlazło, A., 2011. Airborne and dust borne microorganisms in selected polish libraries and archives. Build. Environ. 46, 1872-1879.

Klich, M.A., 2002. Identification of Common Aspergillus Species. CBS, Utrecht, The Netherlands.

Lavin, P., Gómez de Saravia, S.G., Guiamet, P.S., 2010. An environmental assessment of biodeterioration in document repositories. Biofouling 30, 561-569.

Magurran, A.E., 1988. Ecological Diversity and its Measurements. Princeton University Press, Princeton, NJ, pp. 39-40.

Manente, S., Micheluz, A., Ganzerla, R., Ravagnan, G., Gambaro, A., 2012. Chemical and biological characterization of paper: a case study using a proposed methodological approach. Int. Biodeterior. Biodegrad. 74, 99-108.

MIBAC, 2001. Atto d'indirizzo sui criteri tecnico-scientifici e sugli standard di funzionamento e sviluppo dei musei, D.Lgs n.112/98 art.150 comma 6.

Michaelsen, A., Pinar, G., Pinzari, F., 2010. Molecular and microscopical investigation of the microflora inhabiting a deteriorated Italian manuscript dated from the thirteen century. Microb. Ecol. 60, 69-80.

Montanari, M., Melloni, V., Pinzari, F., Innocenti, G., 2012. Fungal biodeterioration of historical library materials stored in compactus movable shelves. Int. Biodeterior. Biodegrad. 75, 83-88.

Montemartini Corte, A., Ferroni, A., Salvo, V.S., 2003. Isolation of fungal species from test samples and maps damaged by foxing, and correlation between these species and the environment. Int. Biodeterior. Biodegrad. 51, 167-173.

Nunes, I., Mesquita, N., Cabo Verde, S., Leitão Bandeira, A.M., Carolino, M.M., Portugal, A., Botelho, M.L., 2013. Characterization of an airborne microbial community: a case study in the archive of the University of Coimbra, Portugal. Int. Biodeterior. Biodegrad. 79, 36-41.

Pasquarella, C., Pitzurra, O., Savino, A., 2000. The index of microbial air contamination. J. Hosp. Infect. 46, 241-256.

Pasquarella, C. Saccani, E., Sansebastiano, G.E., Ugolotti, M., Pasquariello, G., Albertini, R., 2012. Proposal for a biological environmental monitoring approach to be used in libraries and archives. Ann. Agric. Environ. Med. 19 209-212.
Peto, S., Powel, E.O., 1970. The assessment of aerosol concentration by means of the Andersen sampler. J. Appl. Bacteriol. 33, 582-598.

Pinzari, F., Montanari, M., 2008. Il SEM-VP nella diagnostica di alterazioni fungine non più vitali o di difficile caratterizzazione. In: Pinzari, F. (Ed.), Scienza e ricerca per i beni culturali. Microscopia elettronica a scansione e microanalisi. Gangemi Editore, Roma, pp. 79-86.

Pinzari, F., Montanari, M., 2011. Mould growth on library materials stored in compactus-type shelving units. In: Abdul-Wahab Al-Sulaiman, S.A. (Ed.), Sick Building Syndrome: Public Buildings and Workplaces. Springer-Verlag, Berlin Heidelberg, pp. 193-206.

Pitt, J.I., 1979. The Genus Penicillium and its Teleomorphic States: Eupenicillium and Talaromyces. Academic Press.

Pitt, J.I., Hocking, A.D., 1997. Fungi and Food Spoilage. Blackie Academic and Professional of Chapman \& Hall, London, UK.

Raper, K.B., Fennell, D.I., 1965. The Genus Aspergillus. Williams \& Wilkins, Baltimore USA.

Samson, R.A., Lustgraaf, B.V.D., 1978. Aspergillus penicilloides and Eurotium halophilicum in association with house- dust mites. Mycopathologia 64, 13-16.

Samson, R.A., Hoekstra, E.S., Frisvad, J.C., 2004. Introduction to Food and Airborne Fungi. ASM Press, US.

Samson, R.A., Frisvad, J.C., 2004. Penicillium Subgenus Penicillium: New Taxonomic Schemes, Mycotoxins and Other Extrolites. In: Studies in Mycology, vol. 49. CBS, Utrecht, The Netherlands.

Slonczewski, J.L., Coker, A.J., DasSarma, S., 2010. Microbial growth under multiple stressors. Microbe 5, 110-116.

Sterflinger, K., 2010. Fungi: their role in deterioration of cultural heritage. Fungal Biol. Rev. 24, 47-55.

White, T.J., Bruns, T., Lee, S., Taylor, J.W., 1990. Amplification and direct sequencing of fungal ribosomal RNA genes for phylogenetics. In: Innis, M.A., Gelfand, D.H. Sninsky, J.J., White, T.J. (Eds.), PCR Protocols: a Guide to Methods and Applications. Academic Press, New York, pp. 315-322.

Zyska, B., 1997. Fungi isolated from library materials: a review of the literature. Int. Biodeterior. Biodegrad. 40, 43-51. 